\title{
Maria Medina-Vicent. Mujeres y discursos gerenciales: hacia la autogestión feminista. Granada, Comares, 2020
}

\author{
Carlos Jesús Fernández Rodríguez \\ Universidad Autónoma de Madrid, España \\ carlos.fernandez@uam.es
}

En el terreno de los estudios organizacionales, se ha suscitado a lo largo de las últimas décadas un creciente interés por el papel que los denominados discursos gerenciales están desempeñando en la construcción de las nuevas identidades laborales, tanto de directivos de empresas como de empleados. Estos discursos, vinculados a las denominadas ideologías gerenciales o manageriales, son considerados clave a la hora de justificar un compromiso más intenso con el trabajo por parte de los individuos, y presentar dicha conducta como algo atractivo y necesario en el competitivo capitalismo contemporáneo. En los últimos años, los discursos gerenciales han enfatizado que, en el espacio del trabajo, es imprescindible fomentar una atmósfera de entusiasmo que permita incrementar la productividad y creatividad de los empleados, a través de nuevas formas de organización del trabajo y la creación de nuevas "culturas de empresa" en las que se persigue arrancar un mayor compromiso de los trabajadores con sus empleadores. Sin embargo, este compromiso más intenso afecta notablemente a los empleados, al justificar en muchos casos una dedicación extraordinaria y agotadora al trabajo. De hecho, les genera incontables perjuicios personales, familiares y sociales, por la dificultad de dedicar tiempo a otras esferas de la vida, lo que termina provocando en muchas personas un estrés enorme, y problemas derivados de salud y bienestar psicológico. Además, ciertas problemáticas estructurales del capitalismo (la explotación, la dominación patriarcal, la desigualdad, el uso del poder) siguen estando ahí, pese a que en estos discursos se presenta una imagen de la empresa como un espacio dominado por el consenso, la cooperación e incluso, la felicidad.

Indudablemente, uno de los colectivos más afectados por la hegemonía de estas nuevas ideas es, indudablemente, el de las mujeres, pues es habitual que, con independencia de su categoría profesional, ellas sean las que asuman la parte más importante del trabajo doméstico y de los cuidados familiares. Ello las sitúa continuamente en una encrucijada, entre esforzarse más para consolidar su empleo o carrera profesional, o cuidar a sus familias con un cierto equilibrio. Esta dinámica genera incontables presiones a las mujeres, algunas de corte moral, que terminan frenando en muchos casos la progresión en sus profesiones, especialmente en ciertos sectores y, particularmente, en el ámbito de la dirección de empresas, muy exigente en términos de dedicación. Las labores de ejecutivo siguen estando organizadas en torno a la actividad de un hombre sin cargas familiares, con largas jornadas de trabajo, pese a que paradójicamente, en el gerencialismo más moderno se está haciendo un esfuerzo por construir equipos ejecutivos más inclusivos, en los que la diversidad sea la norma y en los que las mujeres pasen a adoptar un rol más importante. Para tratar de resolver la problemática generada por la contradicción entre el rol social tradicionalmente reservado a las mujeres y los objetivos de incrementar 
la productividad de este colectivo, en los últimos años se ha desarrollado una literatura gerencial específicamente dirigida a directivas y empleadas, en las que se tomarían en consideración sus problemas e inquietudes. Se trataría así de una suerte de literatura del management para mujeres, femenina o incluso feminista, que está emergiendo con fuerza y que se sitúa como una corriente novedosa dentro de lo que son los discursos de gestión empresarial actuales.

Este espacio del management femenino, aunque ha recibido cierta atención desde escuelas críticas como los Critical Management Studies, ha sido escasamente analizado en el campo académico español y latinoamericano. Por este motivo, es más que bienvenida la publicación del libro "Mujeres y discursos gerenciales: hacia la autogestión feminista" de la profesora de la Universidad Jaume I Maria Medina-Vicent, la cual cuenta con una muy notable trayectoria de publicaciones a lo largo de los últimos años, particularmente en los estudios de género y la teoría feminista. Este importante trabajo, que supone sin duda alguna una de las contribuciones más importantes de nuestro espacio académico a la comprensión del fenómeno del management, se basa en una magnífica tesis doctoral premiada por varias instituciones, y que aparece ahora publicada en formato libro por la editorial Comares, en una versión más reducida en extensión pero que recoge todas las ideas fundamentales expuestas en la tesis. El objetivo que se plantea Medina-Vicent es el de interpretar los textos más populares de la literatura gerencial dirigida específicamente a las mujeres desde una perspectiva de género, no solamente con el objetivo de desentrañar estos discursos fundamentales para la comprensión de nuestro imaginario social contemporáneo, sino además para añadir una reflexión sobre el feminismo en estos tiempos de hegemonía del pensamiento neoliberal.

El libro consta de cinco capítulos y un apartado de conclusiones. El primer capítulo está dedicado a presentar a los lectores la importancia de los discursos de gestión empresarial, parte fundamental del denominado "nuevo espíritu del capitalismo". En este período histórico marcado por una flexibilidad estructural inherente al régimen de acumulación postfordista, la lógica financiera termina impregnando los valores y acciones de los individuos, con efectos significativos sobre unas subjetividades disciplinadas por la incertidumbre y la precariedad vital. Medina-Vicent persigue comprender los valores y modelos de liderazgo que surgen de la literatura gerencial, una de las principales herramientas de expansión del neoliberalismo por cuanto es la que crea una miriada de significados que estructuran la narrativa contemporánea sobre las bondades del mercado. Las ideas gerenciales fomentan una psicologización y despolitización de las identidades, favoreciendo la popularización de una suerte de pensamiento individualista y "positivo" que merece ser explorado, según Medina-Vicent, desde una perspectiva, la feminista, poco frecuentada en los análisis críticos de la gestión en lengua castellana. En el segundo capítulo del libro, la autora pasa a presentar la literatura gerencial dirigida a mujeres, que va a ser el material empírico analizado en su investigación. Medina-Vicent destaca la relevancia de la masculinización del discurso gerencial, pese a su pretendida neutralidad, y plantea deconstruir las lógicas de los textos de las principales gurús empresariales para tratar de indagar críticamente en el sentido de sus mensajes en torno al rol de la mujer en la dirección de empresas. Tras mencionar que existe una tradición dentro de la literatura gerencial de autoras que han tomado en consideración la condición de la mujer y sus retos específicos en el mundo de la gestión (en particular Rosabeth Moss Kanter), señala que la progresiva incorporación de la mujer a puestos directivos a lo largo de las últimas décadas ha disparado el interés por el liderazgo femenino. De este modo, han surgido autoras con libros de éxito notable (sobre todo, el firmado por Sheryl Sandberg, Consejera Delegada de la famosa compañía Yahoo!) que van a proceder a exponer filosofias de gestión empresarial desde una óptica en la que el género es un elemento clave. 
En el tercer capítulo del libro, Medina-Vicent expone su proyecto, que es el de analizar los discursos gerenciales desde una perspectiva explícitamente feminista, situándose en una intersección entre la filosofia, la sociología y los estudios de género. La autora se pregunta cuál es la pretensión de estos discursos: ¿convertir a las mujeres en sujetos neoliberales? ¿divulgar estilos de liderazgo que perpetúen los estereotipos de género tradicionales? Con el fin de responder a estas cuestiones, la autora presenta un análisis de seis best-sellers seleccionados de la literatura gerencial, entre los que destacan los de la ya citada Sandberg y otro firmado nada menos que por Ivanka Trump, la hija del polémico expresidente norteamericano. Basándose fundamentalmente en la Teoría de la Valoración (Appraisal Theory), Medina-Vicent procederá a analizar las prescripciones presentes en los discursos gerenciales dirigidos a mujeres, con atención preferente a cuatro grandes espacios temáticos: liderazgo femenino, emprendimiento femenino, el papel de la maternidad y la familia y, finalmente, la conciliación entre la esfera laboral y familiar. Los resultados del análisis son extremadamente interesantes, por cuanto de estos libros se infieren las ideas dominantes en el espacio empresarial respecto a la mujer y su estilo de liderazgo que conectan con ciertos estereotipos asociados a la denominada feminidad tradicional. $Y$ es que entre los hallazgos presentados destacan algunos muy notables. Por ejemplo, que ciertas cualidades otorgadas al liderazgo femenino como la emoción, la empatía, el pensamiento relacional o las capacidades de multitarea o inclusividad están impregnadas de un esencialismo ambiguo que le dice a la mujer que puede tener éxito en la empresa si actúa como "mujer". O que una mujer puede tener éxito en el emprendimiento porque tiene, como madre y esposa, gran capacidad de auto-organización que además le permite equilibrar su vida personal y profesional, en un olvido descarado de las desigualdades de género. O que es capaz de planificar su vida a través del análisis más economicista (coste-beneficio de parejas, embarazos), recurriendo además a otras mujeres (niñeras, criadas) para poder conciliar. Medina-Vicent señala que estos argumentos reproducen valores tradicionales y sexistas en relación a la concepción de las mujeres, enfatizando la empatía de estas como rasgo fundamental de su liderazgo frente a otras cualidades, y dejando al final los problemas estructurales de conciliación y desigualdad en los roles familiares en manos de la autogestión de las afectadas, obviando las relaciones sociales de dominación y opresión patriarcal presentes en organizaciones enfocadas exclusivamente a la búsqueda del crudo beneficio económico.

El cuarto capítulo está dedicado al problema de la identidad de la mujer directiva, que se presenta en estos textos gerenciales como algo completamente despolitizado. El neoliberalismo, según la autora del libro, necesita que las mujeres adopten nuevos roles, y pasa a responsabilizarlas de su propio desarrollo profesional. Este marco deriva en un feminismo entendido como una individualización agresiva, en la que cada mujer intenta de alguna forma salvarse a sí mismo, sustituyendo el "nosotras" por el "yo". Se trataría de una suerte de postfeminismo dirigido a las mujeres de clase media y alta en el que, reconociendo los beneficios pasados de la lucha colectiva, se proclama que ha llegado el momento de la lucha personal, individual. Para ello, se recurre, como en otros discursos del management, a la psicologización de las identidades, con énfasis en el pensamiento positivo y la cultura de la felicidad, persiguiendo el empoderamiento y la aceptación de la responsabilidad individual en un contexto de intensa competición mercantil.

El quinto capítulo está dedicado a exponer un análisis sobre el tipo específico de feminismo (entendido como autogestión personal) que recogen estas publicaciones. En un momento de gran popularización mediática del feminismo (con el movimiento Me Too, el 8-M, etc.), ha florecido el interés por la literatura gerencial del feminismo paralelamente a otras nuevas manifestaciones (por ejemplo, manuales para el feminismo y otras piezas de divulgación) que, de acuerdo con Medina-Vicent, corren el riesgo de banalizar o simplificar 
en exceso los contenidos e ideas de la teoría feminista, reduciéndola a una pura filosofía de autogestión personal. Esa mayor presencia del feminismo en el debate público está teniendo recientemente un impacto sobre nuevas obras de literatura gerencial que, aun manteniendo una postura individualista, se dirigen a las mujeres de una forma algo más crítica, señalando la importancia de la confianza y la superación personal no tanto para el éxito como para la autorrealización (la autora pone como ejemplo el libro Feminist Fight Club). Es posible, así, que estemos viviendo un cambio de tendencia en los contenidos y orientación de estos textos. En todo caso, para Medina-Vicent la forma de superación de esta mirada estrecha al feminismo desde el gerencialismo está en la repolitización de las subjetividades y en recordar la importancia de lo colectivo para el feminismo, en el que una ética de la solidaridad y la sororidad es clave para luchar contra las desigualdades. Ello requiere además un reconocimiento de la interdependencia y una apuesta por un proyecto transformador que persiga cambios estructurales y sistémicos en organizaciones y sociedades. El libro finaliza con una breve conclusión en la que se recoge un resumen de los principales contenidos del texto.

Mujeres y discursos gerenciales: hacia la autogestión feminista es, sin lugar a dudas, uno de los textos más importantes publicados en 2020 en las ciencias sociales españolas, y supone una contribución muy relevante a los estudios culturales de la gestión empresarial $\mathrm{y}$, desde luego, a los estudios de género. Aunque el libro cuenta con apenas cien páginas, el esfuerzo de la autora en condensar su extraordinaria tesis doctoral ha dado sin duda sus frutos, y tenemos como resultado final un texto magnífico que va a ser, sin duda, una referencia clásica en lo que llamaríamos unos Critical Management Studies en español, donde la dimensión de género no ha sido explorada en exceso. El libro, además, se sitúa en una intersección entre filosofía, análisis del discurso, sociología y estudios de género que lo convertirá en un ejemplo para estudios interdisciplinares sobre gestión. Confiemos en que el esfuerzo de la profesora Medina-Vicent pueda servir de espoleta para la realización de más análisis con perspectiva de género de las nuevas ideologías gerenciales. 